\title{
Review Article \\ Critical Role of Zinc as Either an Antioxidant or a Prooxidant in Cellular Systems
}

\author{
Sung Ryul Lee $\mathbb{D}$ \\ Department of Convergence Biomedical Science, Cardiovascular and Metabolic Disease Center, College of Medicine, Inje University, \\ Busan, Republic of Korea \\ Correspondence should be addressed to Sung Ryul Lee; lsr1113@inje.ac.kr
}

Received 26 October 2017; Revised 9 January 2018; Accepted 16 January 2018; Published 20 March 2018

Academic Editor: Glenda Gobe

Copyright ( 2018 Sung Ryul Lee. This is an open access article distributed under the Creative Commons Attribution License, which permits unrestricted use, distribution, and reproduction in any medium, provided the original work is properly cited.

\begin{abstract}
Zinc is recognized as an essential trace metal required for human health; its deficiency is strongly associated with neuronal and immune system defects. Although zinc is a redox-inert metal, it functions as an antioxidant through the catalytic action of copper/zinc-superoxide dismutase, stabilization of membrane structure, protection of the protein sulfhydryl groups, and upregulation of the expression of metallothionein, which possesses a metal-binding capacity and also exhibits antioxidant functions. In addition, zinc suppresses anti-inflammatory responses that would otherwise augment oxidative stress. The actions of zinc are not straightforward owing to its numerous roles in biological systems. It has been shown that zinc deficiency and zinc excess cause cellular oxidative stress. To gain insights into the dual action of zinc, as either an antioxidant or a prooxidant, and the conditions under which each role is performed, the oxidative stresses that occur in zinc deficiency and zinc overload in conjunction with the intracellular regulation of free zinc are summarized. Additionally, the regulatory role of zinc in mitochondrial homeostasis and its impact on oxidative stress are briefly addressed.
\end{abstract}

\section{Introduction}

Oxidative stress can be defined as an excessive production of reactive oxygen/nitrogen species (ROS/RNS), known as prooxidants, and/or a deficiency of enzymatic and nonenzymatic antioxidants, which are involved in the detoxification of ROS/RNS [1]. The occurrence of oxidative species is normal in a cell, but excess production occurs when the discharge of oxidants becomes too large for the cellular antioxidant defense mechanisms to detoxify or when the functioning of the antioxidant defense mechanisms is perturbed. Excessive oxidants cause alterations to the normal structure and function of DNA, lipids, and proteins, which trigger mutagenesis and oxidative damage in the cell. Therefore, excessive oxidative stress can generally be considered both a cause and an effect of numerous pathological conditions, such as cancer, neurodegeneration, cardiovascular diseases, diabetes, and kidney diseases, as discussed elsewhere [2-4]. It has been suggested that increased oxidative stress is involved in aging [5]. To combat excessive oxidative stress, various natural or synthetic antioxidants have been evaluated to prevent or attenuate the pathological transition $[2,6-8]$.

In living systems, various metals are involved in a wide variety of biological processes through their action as catalytic and structural components, as discussed elsewhere $[7,9]$. Redox-active metals (e.g., copper and iron) participate in cycling reactions through the transfer of electrons between metals and as substrates to perform redox homeostasis in cellular biochemical reactions. Even these essential metals can cause uncontrolled oxidative stress when their regulation is disturbed $[6,10]$. Toxic metals, such as arsenic and cadmium, which have no apparent biological function, can interact strongly with proteins and DNA [6,7] and cause site-specific damage that results in the conformational change of the proteins and DNA and the excessive production of metal-mediated ROS and RNS [11]. Given the abundant anthropogenic influences in the environment, people may be exposed to these metals via the inhalation of contaminated air, the dietary intake of plant-derived food, and drinking water [12]. Industrial zinc use has increased over time; currently, it is used in galvanization, zinc-based 
alloys, brass, and bronze [13]. Zinc is also used for dental, medical, and household purposes [13]. Previously, the importance of zinc in health and disease has been largely studied from the perspective of severe deficiency with obvious clinical signs $[14,15]$. In contrast with iron, copper, mercury, cadmium, and other metals that accumulate in tissues and produce toxic effects [16], there are fewer disorders associated with the excessive accumulation of zinc [14]. In the long-term high-dose supplementation of zinc, many of the toxic effects associated with zinc are a result of copper deficiency $[17,18]$. Zinc possesses bactericidal properties at low concentrations. This is known as the oligodynamic effect and was identified by Karl Wilhelm von Nägeli through the mechanisms of oxidation-reduction reactions and the intracellular accumulation of ions in bacteria [19]. Moreover, clinical evidence has emphasized the importance of zinc in autodebridement, anti-infective action, and the promotion of epithelialization [20]. It has also been proven that topical administration of zinc in ointments or in bandages was better for disinfection and stimulation of wound healing than oral administration [20].

Zinc belongs to the divalent metals in group 12 of the periodic table and is normally colorless. Unlike other bioactive metals such as iron (ferric state $\left(\mathrm{Fe}^{3+}\right)$ or ferrous state $\left(\mathrm{Fe}^{2+}\right)$ ) and copper (cuprous state $\left(\mathrm{Cu}^{+}\right)$and cupric state $\left(\mathrm{Cu}^{2+}\right)$ ), zinc is stable as a divalent cation $\left(\mathrm{Zn}^{2+}\right)$ and does not directly undergo redox reactions owing to its filled $d$ shell [21]. Compounds containing $\mathrm{Zn}^{1+}$ are rare and require bulky ligands to stabilize the low oxidation state. $\mathrm{Zn}^{2+}$ cannot donate or receive a free electron and it is therefore redox inert; it is not considered an antioxidant in the traditional sense. Instead, $\mathrm{Zn}^{2+}$ can function as an efficient Lewis acid and is often integrated with four ligands into a tetrahedral array with side chains of amino acids such as aspartic acid, glutamic acid, cysteine, and histidine [21, 22]. As indicated by reviews of chronological research events in zinc biology $[23,24]$, the reported biological roles of zinc in health and disease have rapidly increased. Adults have approximately 1.4-2.3 $\mathrm{g}$ of zinc in their body and its content varies significantly between tissues. In this review, $\mathrm{Zn}^{2+}$ refers to the reactive pool of zinc, but "zinc" refers to the total zinc content, which encompasses all forms of zinc including the proteinbound pool (54\%), the exchangeable reactive pool (44.7\%), and $\mathrm{Zn}^{2+}$ [25]. Numerous findings have linked the induction of the enzymes involved in antioxidant defenses and with antioxidant potentials to the action of free or labile forms of $\mathrm{Zn}^{2+}[22,26]$. However, it is not easily discriminable whether the identified actions are derived from zinc or $\mathrm{Zn}^{2+}$. The antioxidant function of zinc was suggested previously [26] and the anti-inflammatory effects of zinc were thereafter rapidly discovered $[27,28]$. Paradoxically, the oxidative stress mediated by zinc deficiency and $\mathrm{Zn}^{2+}$ overload has been suggested to be closely linked to neurodegeneration in Alzheimer's disease [29] and neuronal cultures [30, 31]. Neuronal death that results from excess $\mathrm{Zn}^{2+}$ did not occur because of exogenous zinc, but because of intracellular $\mathrm{Zn}^{2+}$ overload, which was mobilized and redistributed in the brain [32].

The role of zinc as either an antioxidant (Figure 1) or prooxidant (Figure 2) is not straightforward owing to the diversity and complexity of $\mathrm{Zn}^{2+}$ activity. The purpose of this review is to provide an insight into the dual action of zinc, which acts as either an antioxidant or a prooxidant, and the circumstances in which each function is active. First, we have briefly addressed the biochemical and nutritional aspects of zinc. Second, the underlying mechanisms of zinc homeostasis are outlined and the redox involvement of zinc is addressed in conjunction with metallothionein (MT), which is a low-molecular weight cysteine-rich protein with $\mathrm{Zn}^{2+}$-binding capacity [33-35]. Third, the oxidative stresses that occur in zinc deficiency and zinc overload are summarized. Fourth, the regulatory role of zinc in mitochondrial homeostasis and its impact on the oxidative stress have been discussed. Finally, we discussed the role of zinc as either an antioxidant or a prooxidant in conjunction with the intracellular regulation of free zinc.

\section{Biochemical and Nutritional Properties of Zinc}

$\mathrm{Zn}^{2+}$ is an essential heavy metal required by approximately 2800 macromolecules and more than 300 enzymes to build their proper structure and develop their function $[36,37]$. In prokaryotes, approximately $83 \%$ of zinc proteins conduct enzymatic catalysis [38]. Eukaryotes use $\mathrm{Zn}^{2+}$ in diverse biological functions: zinc-related proteins in catalytic reactions (47\%), DNA transcription (44\%), protein transport systems (5\%), and signaling pathways (3\%) [38]. $\mathrm{Zn}^{2+}$ is also involved in stabilization of the membrane structure [39-41], and its deficiency impairs the plasma membrane functions required for platelet aggregation, osmotic protection, and various other processes [41]. Therefore, the widespread deficiency of $\mathrm{Zn}^{2+}$ is likely to result in major health consequences such as severe defects in growth, development, and proper functioning of the reproductive, immune, and neurosensory systems and in behavior, as discussed elsewhere [15, 24, 42]. According to the TOXNET database of the US National Library of Medicine, the oral $50 \%$ lethal dose for zinc is approximately $3 \mathrm{~g} / \mathrm{kg}$ body weight, which is over 10 -fold higher than that for cadmium and 50-fold higher than that for mercury [43]. There are three major routes of entry by which zinc may reach a toxic level in the human body: through the inhalation of zinc oxide as dust or fume, through the skin, or by ingestion. Several studies have demonstrated that exposure to high concentrations of zinc (up to several millimolar) or industrial exposure did not produce severe health concerns [7, 44]. Excessive oral zinc intake (over $150 \mathrm{mg} /$ day) for long periods may induce copper $(\mathrm{Cu})$ deficiency-like symptoms owing to the resulting inhibition of $\mathrm{Cu}$ uptake [45].

$\mathrm{Zn}^{2+}$ is hydrophilic and cannot permeate across the cytoplasmic plasma membrane and the membranes of intracellular compartments. Cellular and whole-body $\mathrm{Zn}^{2+}$ levels are controlled by MTs, $\mathrm{Zn}^{2+}$ transporters (solute carrier family $30 \mathrm{~A}, \mathrm{ZnTs}$ ), and $\mathrm{Zn}^{2+}$ importers (solute carrier family 39A, ZIPs) $[46,47]$. The ZnT family facilitates the mobilization of $\mathrm{Zn}^{2+}$ in the opposite direction of ZIP (as discussed elsewhere [48]). In addition to the ZIP family, 


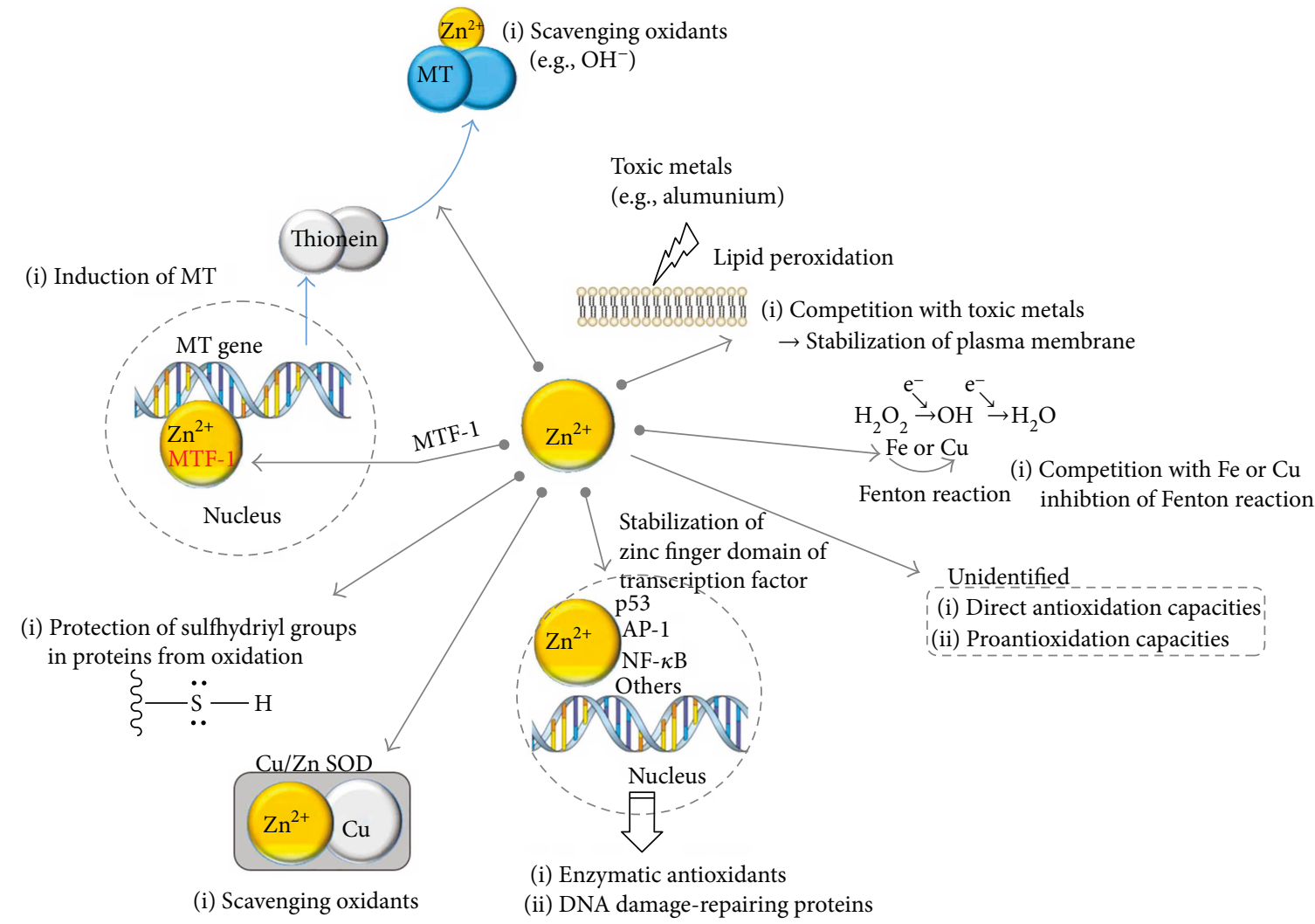

FIGURE 1: Involvement of zinc as an antioxidant. AP-1: activator protein 1; Cu: copper; Fe: iron; MT: metallothionein; MTF-1: metalresponsive transcription factor-1; NF- $\kappa$ B: nuclear factor kappa-B; p53: tumor suppressor p53; SOD: superoxide dismutase.

other membrane transporter proteins, including some types of voltage-gated calcium channels, the glutamate receptor, the acetylcholine receptor, and the transient receptor potential (TRP) channel are involved in mobilization of $\mathrm{Zn}^{2+}$ across the cellular membrane (as discussed elsewhere [49]). In the wound healing process, extracellular $\mathrm{Zn}^{2+}$ released from cellular injuries can be sensed by ZnR/GPR39, which can be triggered by nanomolar concentrations of $\mathrm{Zn}^{2+}$, and promotes signaling that leads to epithelial repair [50]. The increased $\mathrm{Zn}^{2+}$ level in the cytosol will be recognized by the $\mathrm{Zn}^{2+}$-sensitive transcription factor, MTF-1 [51]; once $\mathrm{Zn}^{2+}$ has been bound, MTF-1 translocates to the nucleus to upregulate the expression of MT and ZnTs, such as ZnT1 [52, 53]. Differently, $\mathrm{Zn}^{2+}$ can be buffered within a "zinc muffler" via a still unidentified $\mathrm{Zn}^{2+}$ transporter and is then translocated into an intracellular zinc store, such as the endoplasmic reticulum (ER), Golgi apparatus, lysosomes [54, 55], or mitochondria $[55,56]$. However, there is no clearly identified mechanism through which the intracellular or extracellular level of $\mathrm{Zn}^{2+}$ is exactly sensed.

\section{MT and Its Involvement in the Zinc-Mediated Redox Switch}

MTs have four isoforms (MT I-IV), which show tissuespecific expression. MT I and MT II are ubiquitously expressed but are transcriptionally regulated by the metalresponse element-binding transcription factor-1 (MTF-1);
MT III is predominantly expressed in neurons; and MT IV is dominant in the brain and epithelial tissue (as discussed elsewhere [33, 57]). In contrast to MT I/MT II, both MT III and MT IV are not inducible. MT is located in various cellular compartments, such as the nucleus, cytosol, and cellular organelles [58-60]. MT binds $\mathrm{Zn}^{2+}$ more tightly and at a higher concentration in comparison with other zinc proteins [34]. Four and three zinc ions are captured via their formation of $\alpha$ and $\beta$ clusters with different affinity in MT, respectively $[35,61,62]$. It has been suggested that the specific coordination of the zinc/thiolate clusters in MT [62] will react sensitively to the redox state and thus render flexibility either in cellular availability of $\mathrm{Zn}^{2+}$ or the redistribution of $\mathrm{Zn}^{2+}$ [35]. By contrast, MT can participate in redox chemistry that does not originally result from $\mathrm{Zn}^{2+}$ itself, but rather from its coordination of $\mathrm{Zn}(\mathrm{II})$-thiolate moiety [62-64]. MT is able to scavenge the hydroxyl radical $\left(\mathrm{OH}^{-}\right)$with 300-fold greater efficacy than glutathione $[65,66]$. Moreover, the inherent activity of MT as an antioxidant may be involved in the protection against oxidative damage, such as radiation injury [66] or central nervous system pathology [67]. One of the pathways of MT degradation is its cleavage by lysosomal enzymes, such as cathepsin $\mathrm{B}$, in lysosomes in vivo [52]. Compared with apo-MT, metalbound MT species, such as Zn-MT and cadmium-MT, are extremely resistant to degradation. Metals protect MT against proteolysis, and the degradation of MT and metal release are likely to occur concomitantly [68]. 


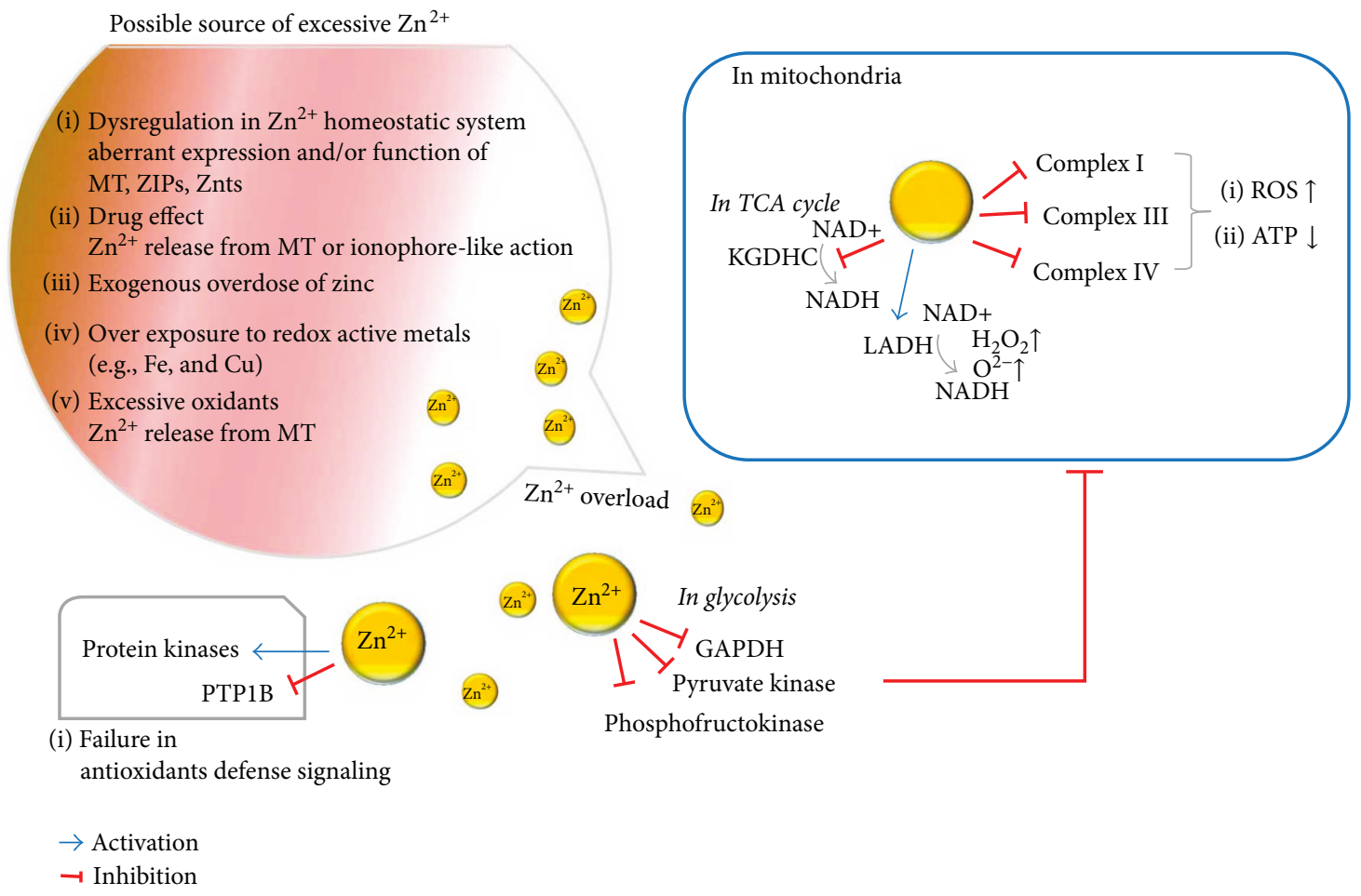

FIGURE 2: Involvement of zinc as a prooxidant. ATP: adenosine triphosphate; complex I: NADH:ubiquinone oxidoreductase; complex III: cytochrome bc1 complex; complex IV: cytochrome c oxidase; GAPDH: glyceraldehyde-3-phosphate dehydrogenase; KGDHC: alpha-ketoglutarate dehydrogenase complex; LADH: lipoamide dehydrogenase; MT: metallothionein; NADH: nicotinamide adenine dinucleotide; PTP1B: protein tyrosine phosphatase 1B; ROS: reactive oxygen species; TCA: tricarboxylic acid, (NADH); ZIP: zinc importer; ZnT: zinc transporter.

\section{Impact of $\mathrm{Zn}^{2+}$ on Mitochondrial Homeostasis and Its Involvement in Oxidative Stress}

Mitochondria are the major source of ROS production $[69,70]$. Therefore, it is valuable to elucidate the role of $\mathrm{Zn}^{2+}$ in mitochondrial functions to obtain further insight into the role of $\mathrm{Zn}^{2+}$ as either an antioxidant or a prooxidant. In the model of ischemia/reperfusion (I/R) injury, the effect of $\mathrm{Zn}^{2+}$ differs between tissues. For example, brain damage during $\mathrm{I} / \mathrm{R}$ can be attenuated by $\mathrm{Zn}^{2+}$ scavenging [71], but cardioprotectants require $\mathrm{Zn}^{2+}$, as discussed elsewhere $[28,72]$. Mitochondria are semiautonomous organelles capable of transcription and translation, and thus, the timely supply of $\mathrm{Zn}^{2+}$ must be supplied for these processes. A reduced content of $\mathrm{Zn}^{2+}$ can affect mitochondrial biogenesis, as matrix-localized metalloproteases that proteolytically cleave newly arrived proteins during their mitochondrial maturation require $\mathrm{Zn}^{2+}$ as a cofactor [73]. $\mathrm{Zn}^{2+}$ is a powerful inhibitor of the redox-regulated Mia40/Erv1 pathway, an essential component of the import pathway used by the small Tim proteins [74]. Thus, an aberrant level of cytosolic $\mathrm{Zn}^{2+}$ could suppress the correct positioning of the mitochondrial proteins required for mitochondrial biogenesis. In addition, zinc deficiency also induces ER stress response owing to accumulation of misfolded proteins that induce a vicious cycle of ER stress and oxidative stress [75, 76]. Improper supply of $\mathrm{Zn}^{2+}$ into mitochondria, for example, an insufficient level of ZnT6 [77] or alcoholic liver disease [78], may compromise many mitochondrial enzymes and proteins involved in mitochondrial protein processing, and thus mitochondrial ROS production can be enhanced owing to mitochondrial dysfunction.

4.1. Glycolysis and TCA Cycle. As shown in Figure 2, several $\mathrm{Zn}^{2+}$-regulated enzymes involved in glycolysis have been identified [79-81]. In addition to zinc deficiency, a high level of $\mathrm{Zn}^{2+}$ can inhibit glycolysis via its inhibitory effects on glyceraldehyde-3-phosphate dehydrogenase (GAPDH) [79], phosphofructokinase [80], and muscle pyruvate kinase [81]; however, these effects can be reversed by a high level of histidine. A high $\mathrm{Zn}^{2+}$ concentration will interrupt the Krebs cycle and mitochondrial ATP production through a decrease in the production of a reduced form of nicotinamide adenine dinucleotide (NADH) [32]. The activity of GAPDH can be inhibited indirectly, because $\mathrm{Zn}^{2+}$ causes a reduction in nicotinamide-adenine dinucleotide $\left(\mathrm{NAD}^{+}\right)$ levels [82]. It should be noted that the $\mathrm{Zn}^{2+}$-mediated inhibition of glycolysis is prominent only in cultured neurons because of their heavy reliance on glycolysis for ATP production compared with the brain [83]. In the tricarboxylic acid (TCA) cycle, the $\alpha$-ketoglutarate dehydrogenase complex, which is an upstream of the bcl complex (complex III), can be suppressed in the presence of a high $\mathrm{Zn}^{2+}$ level [84]. Mitochondrial lipoamide dehydrogenase $(\mathrm{LADH})$, which catalyzes NADH oxidation by oxygen, 
produces hydrogen peroxide as the major product and the superoxide radical as the minor product. As high $\mathrm{Zn}^{2+}$ level does not only activate LADH oxidase but also inhibits both the forward and reverse mode of $\mathrm{LADH}$ thiol oxidoreductase activity, abundant ROS production will occur [85].

4.2. Mitochondrial Respiratory Complexes. $\mathrm{Zn}^{2+}$ can bind slowly and progressively to the active state of complex I (NADH:ubiquinone oxidoreductase), whereas it binds rapidly and tightly to the resting state(s) [86]. At micromolar concentrations, $\mathrm{Zn}^{2+}$ inhibits complex I more strongly than $\mathrm{Mg}^{2+}, \mathrm{Ca}^{2+}, \mathrm{Ba}^{2+}$, and $\mathrm{Mn}^{2+}$ to $\mathrm{Cu}^{2+}$ or $\mathrm{Cd}^{2+}$ through blocking of the proton transfer to bound quinone or proton translocation. Complex II (succinate dehydrogenase $(\mathrm{SDH})$ ), during both the forward and reverse electron transfers, will be suppressed by exposure to low micromolar concentrations of manganese $(\mathrm{Mn})$, and this suppression results in the production of mitochondrial $\mathrm{H}_{2} \mathrm{O}_{2}$ in rat microglial cells, but not astroglial cells [87]. However, $\mathrm{Zn}^{2+}$ does not suppress complex II activity. The electron bifurcation at complex III (cytochrome bc1 complex) is believed to be the most critical electron transfer steps in the respiratory chain [88]. The $\mathrm{Zn}^{2+}$ binding to the bcl complex does not interfere with the binding of either of the substrates, hydroquinone or cytochrome c, but at $100-200 \mathrm{nM}, \mathrm{Zn}^{2+}$ can bind to the hydroquinone center (QP Center) of Fe-S-depleted mitochondrial bcl complexes with high affinity and in a reversible mode; thus, $\mathrm{Zn}$ binding can block a protonatable group in the bc1 complex [89]. Complex IV (cytochrome c oxidase) is a membrane-bound enzyme that catalyzes the reduction of $\mathrm{O}_{2}$ to $\mathrm{H}_{2} \mathrm{O}$ and uses part of the energy released in this reaction to pump protons across the membrane. $\mathrm{Zn}^{2+}$ could inhibit complex IV (cytochrome c oxidase) activity in a biphasic manner [90]. There is less evidence to suggest that $\mathrm{Zn}^{2+}$ is directly involved in changes in complex $\mathrm{V}$ (the $\mathrm{F}_{0} \mathrm{~F}_{1}$ ATP synthase complex) [91].

The inhibition of ETC by high $\mathrm{Zn}^{2+}$ levels may lead to cellular death either via the dissipation of the mitochondrial transmembrane potential $[83,92,93]$, reduced cellular ATP levels [94], or increased ROS production [92]. The mitochondrial permeability transition pore (MPTP) is sensitive to changes in thiol redox status, and thus, $\mathrm{Zn}^{2+}$ can stimulate MPTP opening via interference in thiol recycling [95]. However, it is controversial as to whether $\mathrm{Zn}^{2+}$ can directly induce MPTP opening. Mitochondrial dysfunction is not the sole source of $\mathrm{Zn}^{2+}$-induced cell death, as neuronal cells can be damaged not only by compromised mitochondrial function but also by PI3K-mediated inhibition of mitochondrial movement [96]. In contrast, neuronal cell death was also mediated by $\mathrm{H}_{2} \mathrm{O}_{2}$-induced lysosomal membrane permeabilization owing to the intolerable accumulation of $\mathrm{Zn}^{2+}$ in the lysosome [97].

\section{Role of Zinc as Either an Antioxidant or a Prooxidant in Conjunction with Regulation of Intracellular Free Zinc}

Harmful effects of ROS/RNS can be prevented or slowed by nonenzymatic antioxidants (e.g., alpha-tocopherol, ascorbate, glutathione, and MT) and antioxidant enzymes (e.g., superoxide dismutase (SOD), catalase, and glutathione peroxidase) $[98,99]$. The action of zinc as an antioxidant (Figure 1) is linked to zinc deficiency and disease. However, involvement of cellular zinc decreases in increased levels of ROS and that of RNS is still poorly understood. There is minimal evidence that excessive oxidation/peroxidation primarily occurs in vivo in tissues from zinc-deficient animals [26]. Indeed, a zinc-deficient diet will cause a reduction of food intake in rats $[100,101]$ and thus, multinutritional defects that result from low food intake will be included in the effects of pure zinc deficiency. Unexpectedly, dietary Zn deficiency does not impair the overall antioxidant defense capabilities in any tissue [102] and an uncompromised free radical defense system remains operational [26]. Zinc itself is not redox active, and thus, $\mathrm{Zn}^{2+}$ does not interact directly with ROS or with carbon-centered free radicals [26]. The possible sources of ROS in low zinc levels could be connected to (1) decreased activity of key antioxidant enzymes such as $\mathrm{Cu} / \mathrm{Zn}$-specific SOD. It is known that there is no positive correlation between $\mathrm{Cu} / \mathrm{Zn}-\mathrm{SOD}$ activity and dietary $\mathrm{Zn}$ intake or tissue zinc concentration. The decreased activity of SOD in zinc deficiency might not be a critical factor for oxidative stress, as the overexpression of SOD in yeast did not rescue the oxidative stress levels [103]. In conditions of nutritional stress, the change in $\mathrm{Cu} / \mathrm{Zn}-\mathrm{SOD}$ activity occurs not only through the concentration of $\mathrm{Zn}^{2+}$ but also through the concentration of $\mathrm{Cu}$ [102]. Alternatively, mismetallation in the absence of $\mathrm{Zn}^{2+}$ may be deleterious and yield either an inactive protein or a misfolded state prone to aggregation; (2) disturbance in the induction of MT by $\mathrm{Zn}^{2+}$; (3) lower protection of the free sulfhydryl groups in proteins. $\mathrm{Zn}^{2+}$ can protect the sulfhydryl groups in proteins against oxidation, as shown in $\delta$-aminolevulinate dehydratase, dihydroorotase, the cytoskeletal protein tubulin, and $\mathrm{Zn}$ finger DNA-binding proteins [26]. The interaction of $\mathrm{Zn}^{2+}$ with sulfhydryl groups can be involved in the regulation of enzymatic activity through the prevention of intramolecular disulfide formation, which causes steric hindrance and conformational changes [26]. It is noteworthy that Zn-MT does not protect all sulfhydryl groups against oxidative stress as since $\mathrm{Zn}^{2+}$ will be lost from $\mathrm{Zn}^{2+}$-MT after reaction with $\mathrm{OH}^{-}$and $\mathrm{O}_{2}^{-}$[26]; (4) less competition with redox-active metal ions involved in oxidative reaction. The protein structure of MT can be modified by the reaction with L-homocysteine, and homocysteinylated-MT was reported to lose function and cause increased production of ROS, chronic inflammation, and atherothrombotic disease [104]. $\mathrm{Zn}^{2+}$ can compete with copper or iron for certain types of binding sites, owing to the similarities in their coordination chemistry [105], and thereby suppress their ability to transfer electrons in a particular environment and cause ROS production. For example, competition of $\mathrm{Zn}^{2+}$ with iron and copper in the cell membrane leads to an inhibition of the NADPH oxidase enzyme, another source of $\mathrm{O}_{2}{ }^{-}$and $\mathrm{H}_{2} \mathrm{O}_{2}$ production [106], and attenuates chronic inflammation and hyperglycemia $[11,12]$; (5) dysfunction of the mitochondria and/or ER owing to an insufficiency of zinc; and (6) indirect involvement in oxidative reactions. $\mathrm{Zn}^{2+}$ binds selectively to 
$\mathrm{NADPH}$, but not to NADH. Therefore, $\mathrm{Zn}^{2+}$ can inhibit the $\mathrm{NADPH}$-mediated drug-oxidizing system [107]. $\mathrm{Zn}^{2+}$ can impede the formation of Fe-oxygen-enoic acid complexes, which initiates lipid peroxidation [107]. In addition, $\mathrm{Zn}^{2+}$ can suppress the propagation step of lipid peroxidation at phosphatidylserine, which is where aluminum and related nonredox metals $\left(\mathrm{Sc}^{3+}, \mathrm{Ga}^{3+}, \mathrm{In}^{3+}, \mathrm{Be}^{2+}\right.$, and $\left.\mathrm{Y}^{3+}\right)$ bind preferentially [39]. Hence, $\mathrm{Zn}^{2+}$ performs the role of a stabilizer of macromolecules and biological membranes and minimizes their oxidative/peroxidative damage [40, 41]; although, there are some exceptions $[108,109]$. The pharmacological intake of zinc can confer antioxidant-like functions, as shown in its alimentary effects against acute ethanol toxicity [110], whole-body radiation [111], isoproterenolinduced cardiac oxidative injury [112], and transition metal-mediated site-specific oxidative injury $[113,114]$. It is assumed that zinc participates as an antioxidant [23], as several transcription factors $[27,115]$ can be upregulated by $\mathrm{Zn}^{2+}$ and the antioxidant, detoxifying molecules (glutathione, SOD, glutathione S-transferase, hemeoxygenase-1) and nuclear factor erythroid 2-related factor 2 (Nrf2) can be induced (Figure 1).

In addition to the antioxidant role of zinc (Figure 1), several prooxidant effects mediated by $\mathrm{Zn}^{2+}$ also exist and are highly associated with aberrant increases in $\mathrm{Zn}^{2+}$ levels (Figure 2). With the aberrant expression and function of $\mathrm{Zn}^{2+}$ influx and/or efflux system in conjunction with MT, intracellular $\mathrm{Zn}^{2+}$ overload or $\mathrm{Zn}^{2+}$ deficiency can occur as discussed elsewhere [48, 116-118]. In this type of $\mathrm{Zn}^{2+}$ overload, it will take some time until the detoxifying mechanisms in the cytosol and organelles (e.g., lysosomes and mitochondria) are compromised [119]. In the case of ischemia/ reperfusion or the prevalence of oxidants such as peroxynitrite and methylisothiazolinone, the released $\mathrm{Zn}^{2+}$ from MT or other $\mathrm{Zn}^{2+}$-bound proteins render $\mathrm{Zn}^{2+}$ as a prooxidant as a result of protein misfolding and the subsequent accumulation of these proteins that induces oxidative stress $[35,120]$. Exogenous nitric oxide (NO) or N-methyl-Daspartate (NMDA), which increase the production of endogenous NO via receptor activation leads to peroxynitrite $\left(\mathrm{ONOO}^{-}\right)$formation and then $\mathrm{Zn}^{2+}$ release from intracellular stores, as shown in cerebrocortical neurons [121]. In cardiomyocytes, ROS and/or RNS provide major contributions to a rapid increase in intracellular $\mathrm{Zn}^{2+}$ levels, as a result of the mobilization of $\mathrm{Zn}^{2+}$ from intracellular stores. Moreover, during oxidative stress, including ultraviolet $\mathrm{A}$ irradiation, $\mathrm{Zn}^{2+}$ is released from MTs, either by nitrosylation or oxidation of the thiol ligands. Surgical injury or tissue damage, which releases $\mathrm{Zn}^{2+}$ from damaged cells, leads to a local increase in $\mathrm{Zn}^{2+}$ concentration in the neighboring cells. Certain drugs or metabolites can release $\mathrm{Zn}^{2+}$ from proteins, which will then cause cytotoxic effects. For example, ebselen, a selenium-containing redox drug that mimics the glutathione peroxidase, releases $\mathrm{Zn}^{2+}$ through the oxidation of $\mathrm{Zn}^{2+}$-thiolate clusters in MTs [122]. It should be mentioned that release of $\mathrm{Zn}^{2+}$ from Keap1 by phase II inducers, such as oxidants and electrophiles, dissociates NRF2 from keap1; thus, this mechanism can function as a sensor for the induction of antioxidant responses [123].
Excessive $\mathrm{Zn}^{2+}$ stimulates mitochondrial ROS production, as described in Section 4 . $\mathrm{Zn}^{2+}$-ROS generation (produced by mitochondria, NADPH-oxidase (Nox), and other sources) can trigger further intracellular $\mathrm{Zn}^{2+}$ mobilization. $\mathrm{Zn}^{2+}$ appears to have other metabolic effects that are largely independent of the direct effects on mitochondria (Figure 2). In endothelial cells, aberrant increase in $\mathrm{Zn}^{2+}$ may lead to an increase in Nox1 expression, which contributes to the progression of vascular senescence [124]. Notably, senescent endothelial cells are labile to excess $\mathrm{Zn}^{2+}$ but are resistant to $\mathrm{Zn}^{2+}$ deficiency [125]. Considering the proapoptotic [126] or antiapoptotic role of $\mathrm{Zn}^{2+}$ [127-129], the prosenescence and proapoptotic effects of $\mathrm{Zn}^{2+}$ involved in vascular aging should be further elucidated in the future. In cultured neurons, $\mathrm{Zn}^{2+}$ has been found to trigger the activation of PKC, which results in the induction and activation of Nox1 [130] and also to induce nitric oxide synthase [131], with the resulting generation of $\mathrm{O}^{2-}, \mathrm{NO}$, and peroxynitrite [131]. In contrast, $\mathrm{Zn}^{2+}$ itself can induce protein kinase C- (PKC-) dependent MT phosphorylation, which results in the amplification of acute $\mathrm{Zn}^{2+}$ increases during in vitro brain ischemia [132]. Excessive $\mathrm{Zn}^{2+}$ distorts the signaling pathways, and this effect may lead to disruption of cellular homeostasis (Figure 2). For example, $\mathrm{Zn}^{2+}$ can inhibit the protein tyrosine phosphatase 1B (PTP 1B) and consequently activate the numerous kinases targeted by PTP $1 \mathrm{~B}$. This uncontrolled activation of kinases results in mitochondrial dysfunction and the activation of transcription factors such as Egr-1 or Elk-1, which leads to caspase-independent cell death [133].

\section{Conclusion}

$\mathrm{Zn}^{2+}$ performs versatile functions involved in the structural development and catalysis of enzymes and in signal mediation in biological system. One of these functions is that the important component of $\mathrm{Zn}^{2+}$ in redox regulation works as an essential component in $\mathrm{Cu} / \mathrm{Zn} \mathrm{SOD}$ and antioxidant via the control of cellular signal transduction, such as gene regulation (e.g., p53, NF- $\kappa \mathrm{B}$, and AP-1) and enzymatic activities. Numerous trials of $\mathrm{Zn}^{2+}$ supplements and topical delivery were indicated to provide beneficial impacts on health and the amelioration of pathological conditions. An adequate supply of zinc is considered essential in slowing the aging process, which in turn leads to improved cognitive functions, immune functions, stress response, and age-related neurodegenerative disorders [11]. In addition to alcoholism, zinc chelators were shown to facilitate some opioid-withdrawal signs in animals. Zinc deficiency, which affects more than $15 \%$ of the world's population, is also common among opioid consumers, and opioid-treated animals exhibit imbalances in zinc distribution [134]. As shown clinically, $\mathrm{Zn}^{2+}$ overload occurs in rare cases but its increase causes oxidative stress via the suppression of metabolism and mitochondrial functions. Several causes that lead to the increase of $\mathrm{Zn}^{2+}$ were addressed in the previous sections. Aberrant release from binding sites, such as MT, and/or from deposits in the organelles, such as mitochondria and lysosomes [55], will cause secondary oxidative stress initiated by mitochondrial 
and oxidant-producing enzymes. Numerous findings have suggested that excessive $\mathrm{Zn}^{2+}$ caused oxidative stress owing to its role as a prooxidant and eventually caused cellular death. However, it should be mentioned that numerous biomedical studies have employed irrelevant $\mathrm{Zn}^{2+}$ conditions, including the use of the supraphysiological concentrations of zinc, and various forms of zinc [97]. In addition, when high levels of $\mathrm{Zn}$ are administered orally or by injection, there may be numerous differences in the tissue distribution, metabolism, excretion, interaction, and overall homeostasis of $\mathrm{Zn}$ in the whole animal system [26]. In understanding of the role of $\mathrm{Zn}^{2+}$ as either an antioxidant or a prooxidant, the time window of $\mathrm{Zn}^{2+}$ effects presents another concern, as the enzymatic antioxidant systems will have a lag time for their induction whereas nonenzymatic antioxidant systems are not largely affected by $\mathrm{Zn}^{2+}$. In addition, an abrupt increase of $\mathrm{Zn}^{2+}$ will be caused either by highly oxidative conditions or by failure of $\mathrm{Zn}^{2+}$ homeostasis; therefore, its direct role in the antioxidant defense responses is unclear. When considering the inhibitory effect of $\mathrm{Zn}^{2+}$ on metabolic and mitochondrial function, augmentation of ROS production by $\mathrm{Zn}^{2+}$ will be more prominent. Many signaling pathways can be activated or inhibited by $\mathrm{Zn}^{2+}[24,135,136]$. Currently, it is hard to predict where $\mathrm{Zn}^{2+}$ will drive a cellular response. The exclusive role of $\mathrm{Zn}^{2+}$ as a prooxidant cannot be separated from the innate oxidative stresses caused by other factors, as the existence of excessive oxidants exaggerates the increased $\mathrm{Zn}^{2+}$ in any given system. The putative effects of zinc supplementation or deficiency may be significantly affected by the concomitant changes in MT I/II expression. In addition to zinc transporters, the status of aberrant expression or mutation of MTs [48] will influence the expected antioxidant roles of $\mathrm{Zn}^{2+}$, because various biological functions of $\mathrm{Zn}^{2+}$ are cooperated with MTs, which aid in controlling the concentration of $\mathrm{Zn}^{2+}$ at critical sites. Indeed, the optimal amount of free $\mathrm{Zn}^{2+}$ and the deleterious impact of $\mathrm{Zn}^{2+}$ on the cellular system are complex and frequently seem to be less responsive to nutritional supplement with zinc [7]. The precise measurement of total zinc and free zinc levels in either healthy or pathological conditions allows the decision of the dose and duration of optimal zinc supplementation and maintenance. Recently, the examination of metal ionophores (e.g., dithiocarbamates and pyrithione) is in progress in cancer cell biology for their potential clinical use [137]. Metal chelators, such as desferrioxamine and tetrathiomolybdate, will suppress the availability of $\mathrm{Zn}^{2+}$, even at normal zinc levels. It is reasonable that more attention should be paid to the specific effects of $\mathrm{Zn}^{2+}$-chelator or ionophores involved in the oxidative responses in conjunction with the behavior of $\mathrm{Zn}^{2+}$.

In this review, we have briefly outlined why both $\mathrm{Zn}^{2+}$ deficiency and $\mathrm{Zn}^{2+}$ overload could contribute to oxidative stress. Zinc, an essential metal for life, plays important roles as an antioxidant to combat and suppress oxidative stress. In contrast, the excessive presence of $\mathrm{Zn}^{2+}$ triggers harmful oxidative stress. Therefore, strategies to enhance the antioxidant activity of $\mathrm{Zn}^{2+}$ while minimizing the induction of prooxidant effects should be the subject of future studies. Despite the numerous technical hurdles, the targeted and controlled delivery of $\mathrm{Zn}^{2+}$ and/or chelators to specific areas or tissues should be established for both clinical and scientific purposes.

\section{Disclosure}

The author apologizes for the vast number of outstanding publications that could not be cited owing to space limitations.

\section{Conflicts of Interest}

The author declares that there are no conflicts of interest.

\section{Acknowledgments}

This work was supported by the Basic Science Research Program (2015R1D1A3A 01015596) through the National Research Foundation of Korea (NRF) funded by the Ministry of Education, Science, and Technology.

\section{References}

[1] H. Sies, "Oxidative stress: from basic research to clinical application," The American Journal of Medicine, vol. 91, no. 3, Supplement 3, pp. S31-S38, 1991.

[2] A. M. Pisoschi and A. Pop, "The role of antioxidants in the chemistry of oxidative stress: a review," European Journal of Medicinal Chemistry, vol. 97, pp. 55-74, 2015.

[3] B. Poljsak, D. Suput, and I. Milisav, "Achieving the balance between ROS and antioxidants: when to use the synthetic antioxidants," Oxidative Medicine and Cellular Longevity, vol. 2013, Article ID 956792, 11 pages, 2013.

[4] P. I. Oteiza, G. G. Mackenzie, and S. V. Verstraeten, "Metals in neurodegeneration: involvement of oxidants and oxidantsensitive transcription factors," Molecular Aspects of Medicine, vol. 25, no. 1-2, pp. 103-115, 2004.

[5] I. Korovila, M. Hugo, J. P. Castro et al., "Proteostasis, oxidative stress and aging," Redox Biology, vol. 13, pp. 550-567, 2017.

[6] S. J. S. Flora, "Structural, chemical and biological aspects of antioxidants for strategies against metal and metalloid exposure," Oxidative Medicine and Cellular Longevity, vol. 2, no. 4, pp. 191-206, 2009.

[7] K. Jomova and M. Valko, "Advances in metal-induced oxidative stress and human disease," Toxicology, vol. 283, no. 2-3, pp. 65-87, 2011.

[8] P. Poprac, K. Jomova, M. Simunkova, V. Kollar, C. J. Rhodes, and M. Valko, "Targeting free radicals in oxidative stressrelated human diseases," Trends in Pharmacological Sciences, vol. 38, no. 7, pp. 592-607, 2017.

[9] M. Valko, K. Jomova, C. J. Rhodes, K. Kuča, and K. Musílek, "Redox- and non-redox-metal-induced formation of free radicals and their role in human disease," Archives of Toxicology, vol. 90, no. 1, pp. 1-37, 2016.

[10] C. W. Siah, D. Trinder, and J. K. Olynyk, "Iron overload," Clinica Chimica Acta, vol. 358, no. 1-2, pp. 24-36, 2005.

[11] E. Mocchegiani, L. Costarelli, R. Giacconi, F. Piacenza, A. Basso, and M. Malavolta, "Zinc, metallothioneins and immunosenescence: effect of zinc supply as nutrigenomic approach," Biogerontology, vol. 12, no. 5, pp. 455-465, 2011. 
[12] S. Clemens and J. F. Ma, "Toxic heavy metal and metalloid accumulation in crop plants and foods," Annual Review of Plant Biology, vol. 67, no. 1, pp. 489-512, 2016.

[13] A. C. Tolcin, 2009 Minerals Yearbook, United States Geological Survey, Washington, DC, USA, 2011.

[14] J. E. Cummings and J. P. Kovacic, "The ubiquitous role of zinc in health and disease," Journal of Veterinary Emergency and Critical Care, vol. 19, no. 3, pp. 215-240, 2009.

[15] K. Jurowski, B. Szewczyk, G. Nowak, and W. Piekoszewski, "Biological consequences of zinc deficiency in the pathomechanisms of selected diseases," JBIC Journal of Biological Inorganic Chemistry, vol. 19, no. 7, pp. 1069-1079, 2014.

[16] A. S. Prasad, "Essentiality and toxicity of zinc," Scandinavian Journal of Work, Environment \& Health, vol. 19, Supplement 1, pp. 134-136, 1993.

[17] H. N. Hoffman II, R. L. Phyliky, and C. R. Fleming, "Zincinduced copper deficiency," Gastroenterology, vol. 94, no. 2, pp. 508-512, 1988.

[18] S. R. Simon, R. F. Branda, B. H. Tindle, and S. L. Burns, "Copper deficiency and sideroblastic anemia associated with zinc ingestion," American Journal of Hematology, vol. 28, no. 3, pp. 181-183, 1988.

[19] M. Yasuyuki, K. Kunihiro, S. Kurissery, N. Kanavillil, Y. Sato, and Y. Kikuchi, "Antibacterial properties of nine pure metals: a laboratory study using Staphylococcus aureus and Escherichia coli," Biofouling, vol. 26, no. 7, pp. 851-858, 2010.

[20] A. B. G. Lansdown, U. Mirastschijski, N. Stubbs, E. Scanlon, and M. S. Ågren, "Zinc in wound healing: theoretical, experimental, and clinical aspects," Wound Repair and Regeneration, vol. 15, no. 1, pp. 2-16, 2007.

[21] K. L. Haas and K. J. Franz, "Application of metal coordination chemistry to explore and manipulate cell biology," Chemical Reviews, vol. 109, no. 10, pp. 4921-4960, 2009.

[22] T. Kochanczyk, A. Drozd, and A. Krezel, "Relationship between the architecture of zinc coordination and zinc binding affinity in proteins - insights into zinc regulation," Metallomics, vol. 7, no. 2, pp. 244-257, 2015.

[23] W. Maret, "Zinc biochemistry: from a single zinc enzyme to a key element of life," Advances in Nutrition, vol. 4, no. 1, pp. 82-91, 2013.

[24] T. Fukada and T. Kambe, Eds., Zinc Signals in Cellular Functions and Disorders, Springer, Tokyo, Japan, 2014.

[25] L. C. Costello, C. C. Fenselau, and R. B. Franklin, "Evidence for operation of the direct zinc ligand exchange mechanism for trafficking, transport, and reactivity of zinc in mammalian cells," Journal of Inorganic Biochemistry, vol. 105, no. 5, pp. 589-599, 2011.

[26] T. M. Bray and W. J. Bettger, "The physiological role of zinc as an antioxidant," Free Radical Biology \& Medicine, vol. 8, no. 3, pp. 281-291, 1990.

[27] M. Jarosz, M. Olbert, G. Wyszogrodzka, K. Młyniec, and T. Librowski, "Antioxidant and anti-inflammatory effects of zinc. Zinc-dependent NF- $\kappa \mathrm{B}$ signaling," Inflammopharmacology, vol. 25, no. 1, pp. 11-24, 2017.

[28] N. Efeovbokhan, S. K. Bhattacharya, R. A. Ahokas et al., "Zinc and the prooxidant heart failure phenotype," Journal of Cardiovascular Pharmacology, vol. 64, no. 4, pp. 393-400, 2014.

[29] Y. Yuan, F. Niu, Y. Liu, and N. Lu, "Zinc and its effects on oxidative stress in Alzheimer's disease," Neurological Sciences, vol. 35, no. 6, pp. 923-928, 2014.
[30] A. Clausen, T. McClanahan, S. G. Ji, and J. H. Weiss, "Mechanisms of rapid reactive oxygen species generation in response to cytosolic $\mathrm{Ca}^{2+}$ or $\mathrm{Zn}^{2+}$ loads in cortical neurons," PLoS One, vol. 8, no. 12, article e83347, 2013.

[31] Y. H. Kim, E. Y. Kim, B. J. Gwag, S. Sohn, and J. Y. Koh, "Zinc-induced cortical neuronal death with features of apoptosis and necrosis: mediation by free radicals," Neuroscience, vol. 89, no. 1, pp. 175-182, 1999.

[32] J. Y. Koh, S. W. Suh, B. J. Gwag, Y. Y. He, C. Y. Hsu, and D. W. Choi, "The role of zinc in selective neuronal death after transient global cerebral ischemia," Science, vol. 272, no. 5264, pp. 1013-1016, 1996.

[33] R. D. Palmiter, "The elusive function of metallothioneins," Proceedings of the National Academy of Sciences of the United States of America, vol. 95, no. 15, pp. 8428-8430, 1998.

[34] W. Maret, "The function of zinc metallothionein: a link between cellular zinc and redox state," The Journal of Nutrition, vol. 130, no. 5, pp. 1455S-1458S, 2000.

[35] W. Maret, "Metallothionein redox biology in the cytoprotective and cytotoxic functions of zinc," Experimental Gerontology, vol. 43, no. 5, pp. 363-369, 2008.

[36] C. Andreini, L. Banci, I. Bertini, and A. Rosato, "Counting the zinc-proteins encoded in the human genome," Journal of Proteome Research, vol. 5, no. 1, pp. 196-201, 2006.

[37] C. Andreini and I. Bertini, "A bioinformatics view of zinc enzymes," Journal of Inorganic Biochemistry, vol. 111, pp. 150-156, 2012.

[38] C. Andreini, I. Bertini, and A. Rosato, "Metalloproteomes: a bioinformatic approach," Accounts of Chemical Research, vol. 42, no. 10, pp. 1471-1479, 2009.

[39] S. V. Verstraeten, L. V. Nogueira, S. Schreier, and P. I. Oteiza, "Effect of trivalent metal ions on phase separation and membrane lipid packing: role in lipid peroxidation," Archives of Biochemistry and Biophysics, vol. 338, no. 1, pp. 121127, 1997.

[40] M. Chvapil, "New aspects in the biological role of zinc: a stabilizer of macromolecules and biological membranes," Life Sciences, vol. 13, no. 8, pp. 1041-1049, 1973.

[41] B. L. O'Dell, "Role of zinc in plasma membrane function," The Journal of Nutrition, vol. 130, no. 5, pp. 1432S1436S, 2000.

[42] M. Stefanidou, C. Maravelias, A. Dona, and C. Spiliopoulou, "Zinc: a multipurpose trace element," Archives of Toxicology, vol. 80, no. 1, pp. 1-9, 2006

[43] L. M. Plum, L. Rink, and H. Haase, "The essential toxin: impact of zinc on human health," International Journal of Environmental Research and Public Health, vol. 7, no. 12, pp. 1342-1365, 2010.

[44] J. J. Langham Brown, "Zinc fume fever," The British Institute of Radiology, vol. 61, no. 724, pp. 327-329, 1988.

[45] A. S. Prasad, G. J. Brewer, E. B. Schoomaker, and P. Rabbani, "Hypocupremia induced by zinc therapy in adults," JAMA, vol. 240, no. 20, pp. 2166-2168, 1978.

[46] J. P. Liuzzi and R. J. Cousins, "Mammalian zinc transporters," Annual Review of Nutrition, vol. 24, no. 1, pp. 151-172, 2004.

[47] D. J. Eide, "Zinc transporters and the cellular trafficking of zinc," Biochimica et Biophysica Acta (BBA) - Molecular Cell Research, vol. 1763, no. 7, pp. 711-722, 2006.

[48] T. Kimura and T. Kambe, "The functions of metallothionein and ZIP and ZnT transporters: an overview and perspective," 
International Journal of Molecular Sciences, vol. 17, no. 12, p. 336, 2016.

[49] A. Bouron and J. Oberwinkler, "Contribution of calciumconducting channels to the transport of zinc ions," Pflügers Archiv, vol. 466, no. 3, pp. 381-387, 2014.

[50] H. Sharir, A. Zinger, A. Nevo, I. Sekler, and M. Hershfinkel, "Zinc released from injured cells is acting via the $\mathrm{Zn}^{2+}$-sensing receptor, $\mathrm{ZnR}$, to trigger signaling leading to epithelial repair," The Journal of Biological Chemistry, vol. 285, no. 34, pp. 26097-26106, 2010.

[51] T. Kimura, N. Itoh, and G. K. Andrews, "Mechanisms of heavy metal sensing by metal response element-binding transcription factor-1," Journal of Health Science, vol. 55, no. 4, pp. 484-494, 2009.

[52] I. Bremner and N. T. Davies, "The induction of metallothionein in rat liver by zinc injection and restriction of food intake," Biochemical Journal, vol. 149, no. 3, pp. 733-738, 1975.

[53] G. K. Andrews, "Cellular zinc sensors: MTF-1 regulation of gene expression," Biometals, vol. 14, no. 3/4, pp. 223237, 2001.

[54] I. Kukic, S. L. Kelleher, and K. Kiselyov, " $\mathrm{Zn}^{2+}$ efflux through lysosomal exocytosis prevents $\mathrm{Zn}^{2+}$-induced toxicity," Journal of Cell Science, vol. 127, no. 14, pp. 3094-3103, 2014.

[55] Q. Lu, H. Haragopal, K. G. Slepchenko, C. Stork, and Y. V. Li, "Intracellular zinc distribution in mitochondria, ER and the Golgi apparatus," International Journal of Physiology, Pathophysiology and Pharmacology, vol. 8, no. 1, pp. 35-43, 2016.

[56] R. A. Colvin, A. I. Bush, I. Volitakis et al., "Insights into $\mathrm{Zn}^{2+}$ homeostasis in neurons from experimental and modeling studies," American Journal of Physiology-Cell Physiology, vol. 294, no. 3, pp. C726-C742, 2008.

[57] D. Juárez-Rebollar, C. Rios, C. Nava-Ruíz, and M. MéndezArmenta, "Metallothionein in brain disorders," Oxidative Medicine and Cellular Longevity, vol. 2017, Article ID 5828056, 12 pages, 2017.

[58] Z. Zhou and Y. J. Kang, "Immunocytochemical localization of metallothionein and its relation to doxorubicin toxicity in transgenic mouse heart," The American Journal of Pathology, vol. 156, no. 5, pp. 1653-1662, 2000.

[59] B. Ye, W. Maret, and B. L. Vallee, "Zinc metallothionein imported into liver mitochondria modulates respiration," Proceedings of the National Academy of Sciences of the United States of America, vol. 98, no. 5, pp. 2317-2322, 2001.

[60] S. R. Hennigar and S. L. Kelleher, "Zinc networks: the cell-specific compartmentalization of zinc for specialized functions," Biological Chemistry, vol. 393, no. 7, pp. 565$578,2012$.

[61] A. H. Robbins, D. McRee, M. Williamson et al., "Refined crystal structure of $\mathrm{Cd}, \mathrm{Zn}$ metallothionein at 2.0Åresolution," Journal of Molecular Biology, vol. 221, no. 4, pp. 1269-1293, 1991.

[62] A. Krezel and W. Maret, "Different redox states of metallothionein/thionein in biological tissue," Biochemical Journal, vol. 402, no. 3, pp. 551-558, 2007.

[63] W. Maret, "Metallothionein/disulfide interactions, oxidative stress, and the mobilization of cellular zinc," Neurochemistry International, vol. 27, no. 1, pp. 111-117, 1995.

[64] N. M. Giles, A. B. Watts, G. I. Giles, F. H. Fry, J. A. Littlechild, and C. Jacob, "Metal and redox modulation of cysteine protein function," Chemistry \& Biology, vol. 10, no. 8, pp. 677-693, 2003.

[65] M. Sato and I. Bremner, "Oxygen free radicals and metallothionein," Free Radical Biology \& Medicine, vol. 14, no. 3, pp. 325-337, 1993.

[66] P. J. Thornalley and M. Vasak, "Possible role for metallothionein in protection against radiation-induced oxidative stress. Kinetics and mechanism of its reaction with superoxide and hydroxyl radicals," Biochimica et Biophysica Acta (BBA) Protein Structure and Molecular Enzymology, vol. 827, no. 1, pp. 36-44, 1985.

[67] M. Penkowa, "Metallothioneins are multipurpose neuroprotectants during brain pathology," The FEBS Journal, vol. 273, no. 9, pp. 1857-1870, 2006.

[68] C. D. Klaassen, S. Choudhuri, J. M. McKim, L. D. LehmanMcKeeman, and W. C. Kershaw, "In vitro and in vivo studies on the degradation of metallothionein," Environ Health Perspect, vol. 102, Supplement 3, pp. 141-146, 1994.

[69] J. F. Turrens, "Mitochondrial formation of reactive oxygen species," The Journal of Physiology, vol. 552, no. 2, pp. 335344, 2003.

[70] F. L. Muller, Y. Liu, and H. Van Remmen, "Complex III releases superoxide to both sides of the inner mitochondrial membrane," The Journal of Biological Chemistry, vol. 279, no. 47, pp. 49064-49073, 2004.

[71] C. W. Shuttleworth and J. H. Weiss, "Zinc: new clues to diverse roles in brain ischemia," Trends in Pharmacological Sciences, vol. 32, no. 8, pp. 480-486, 2011.

[72] Z. Xu and J. Zhou, "Zinc and myocardial ischemia/reperfusion injury," Biometals, vol. 26, no. 6, pp. 863-878, 2013.

[73] A. B. Taylor, B. S. Smith, S. Kitada et al., "Crystal structures of mitochondrial processing peptidase reveal the mode for specific cleavage of import signal sequences," Structure, vol. 9, no. 7, pp. 615-625, 2001.

[74] B. Morgan, S. K. Ang, G. Yan, and H. Lu, "Zinc can play chaperone-like and inhibitor roles during import of mitochondrial small Tim proteins," The Journal of Biological Chemistry, vol. 284, no. 11, pp. 6818-6825, 2009.

[75] C. D. Ellis, F. Wang, C. W. MacDiarmid, S. Clark, T. Lyons, and D. J. Eide, "Zinc and the Msc2 zinc transporter protein are required for endoplasmic reticulum function," The Journal of Cell Biology, vol. 166, no. 3, pp. 325-335, 2004.

[76] J. D. Malhotra, H. Miao, K. Zhang et al., "Antioxidants reduce endoplasmic reticulum stress and improve protein secretion," Proceedings of the National Academy of Sciences of the United States of America, vol. 105, no. 47, pp. 18525-18530, 2008.

[77] E. Napoli, C. Ross-Inta, S. Wong et al., “Altered zinc transport disrupts mitochondrial protein processing/import in fragile X-associated tremor/ataxia syndrome," Human Molecular Genetics, vol. 20, no. 15, pp. 3079-3092, 2011.

[78] Q. Sun, W. Zhong, W. Zhang, and Z. Zhou, "Defect of mitochondrial respiratory chain is a mechanism of ROS overproduction in a rat model of alcoholic liver disease: role of zinc deficiency," American Journal of Physiology-Gastrointestinal and Liver Physiology, vol. 310, no. 3, pp. G205-G214, 2016.

[79] B. Krotkiewska and T. Banas, "Interaction of $\mathrm{Zn}^{2+}$, and $\mathrm{Cu}^{2+}$, ions with glyceraldehyde-3-phosphate dehydrogenase from bovine heart and rabbit muscle," The International Journal of Biochemistry, vol. 24, no. 9, pp. 1501-1505, 1992.

[80] T. Ikeda, K. Kimura, S. Morioka, and N. Tamaki, "Inhibitory effects of $\mathrm{Zn}^{2+}$ on muscle glycolysis and their reversal by 
histidine," Journal of Nutritional Science and Vitaminology, vol. 26, no. 4, pp. 357-366, 1980.

[81] N. Tamaki, T. Ikeda, K. Kimura, and S. Morioka, "Inhibitory effect of $\mathrm{Zn}^{2+}$ on rabbit muscle pyruvate kinase and reactivation by histidine," Journal of Nutritional Science and Vitaminology, vol. 27, no. 2, pp. 107-116, 1981.

[82] C. T. Sheline, M. M. Behrens, and D. W. Choi, "Zinc-induced cortical neuronal death: contribution of energy failure attributable to loss of $\mathrm{NAD}^{+}$and inhibition of glycolysis," The Journal of Neuroscience, vol. 20, no. 9, pp. 3139-3146, 2000.

[83] K. E. Dineley, T. V. Votyakova, and I. J. Reynolds, "Zinc inhibition of cellular energy production: implications for mitochondria and neurodegeneration," Journal of Neurochemistry, vol. 85, no. 3, pp. 563-570, 2003.

[84] A. M. Brown, B. S. Kristal, M. S. Effron et al., " $\mathrm{Zn}^{2+}$ inhibits $\alpha$-ketoglutarate-stimulated mitochondrial respiration and the isolated $\alpha$-ketoglutarate dehydrogenase complex," The Journal of Biological Chemistry, vol. 275, no. 18, pp. 13441-13447, 2000.

[85] I. G. Gazaryan, B. F. Krasnikov, G. A. Ashby, R. N. F. Thorneley, B. S. Kristal, and A. M. Brown, "Zinc is a potent inhibitor of thiol oxidoreductase activity and stimulates reactive oxygen species production by lipoamide dehydrogenase," The Journal of Biological Chemistry, vol. 277, no. 12, pp. 10064-10072, 2002.

[86] M. S. Sharpley and J. Hirst, "The inhibition of mitochondrial complex I (NADH:ubiquinone oxidoreductase) by $\mathrm{Zn}^{2+}$," The Journal of Biological Chemistry, vol. 281, no. 46, pp. 34803-34809, 2006.

[87] Y. Liu, D. S. Barber, P. Zhang, and B. Liu, "Complex II of the mitochondrial respiratory chain is the key mediator of divalent manganese-induced hydrogen peroxide production in microglia," Toxicological Sciences, vol. 132, no. 2, pp. 298-306, 2013.

[88] H. Nohl, L. Gille, A. Kozlov, and K. Staniek, “Are mitochondria a spontaneous and permanent source of reactive oxygen species?," Redox Report, vol. 8, no. 3, pp. 135-141, 2003.

[89] T. A. Link and G. von Jagow, "Zinc ions inhibit the $Q_{P}$ center of bovine heart mitochondrial $b c_{1}$ complex by blocking a protonatable group," The Journal of Biological Chemistry, vol. 270, no. 42, pp. 25001-25006, 1995.

[90] S. S. Kuznetsova, N. V. Azarkina, T. V. Vygodina, S. A. Siletsky, and A. A. Konstantinov, "Zinc ions as cytochrome C oxidase inhibitors: two sites of action," Biochemistry, vol. 70, no. 2, pp. 128-136, 2005.

[91] W. Rouslin, C. W. Broge, and B. V. Chernyak, "Effects of $\mathrm{Zn}^{2+}$ on the activity and binding of the mitochondrial ATPase inhibitor protein, $\mathrm{IF}_{1}$," Journal of Bioenergetics and Biomembranes, vol. 25, no. 3, pp. 297-306, 1993.

[92] S. L. Sensi, H. Z. Yin, S. G. Carriedo, S. S. Rao, and J. H. Weiss, "Preferential $\mathrm{Zn}^{2+}$ influx through $\mathrm{Ca}^{2+}$-permeable AMPA/ kainate channels triggers prolonged mitochondrial superoxide production," Proceedings of the National Academy of Sciences of the United States of America, vol. 96, no. 5, pp. 2414-2419, 1999.

[93] K. E. Dineley, L. L. Richards, T. V. Votyakova, and I. J. Reynolds, "Zinc causes loss of membrane potential and elevates reactive oxygen species in rat brain mitochondria," Mitochondrion, vol. 5, no. 1, pp. 55-65, 2005.

[94] K. E. Dineley, J. M. Scanlon, G. J. Kress, A. K. Stout, and I. J. Reynolds, "Astrocytes are more resistant than neurons to the cytotoxic effects of increased $\left[\mathrm{Zn}^{2+}\right]_{\mathrm{i}}$, , Neurobiology of Disease, vol. 7, no. 4, pp. 310-320, 2000.

[95] V. Petronilli, P. Costantini, L. Scorrano, R. Colonna, S. Passamonti, and P. Bernardi, "The voltage sensor of the mitochondrial permeability transition pore is tuned by the oxidation-reduction state of vicinal thiols. Increase of the gating potential by oxidants and its reversal by reducing agents," The Journal of Biological Chemistry, vol. 269, no. 24, pp. 16638-16642, 1994.

[96] L. M. Malaiyandi, A. S. Honick, G. L. Rintoul, Q. J. Wang, and I. J. Reynolds, " $\mathrm{Zn}^{2+}$ inhibits mitochondrial movement in neurons by phosphatidylinositol 3-kinase activation," The Journal of Neuroscience, vol. 25, no. 41, pp. 9507-9514, 2005.

[97] J. J. Hwang, S. J. Lee, T. Y. Kim, J. H. Cho, and J. Y. Koh, “Zinc and 4-hydroxy-2-nonenal mediate lysosomal membrane permeabilization induced by $\mathrm{H}_{2} \mathrm{O}_{2}$ in cultured hippocampal neurons," The Journal of Neuroscience, vol. 28, no. 12, pp. 3114-3122, 2008.

[98] J. M. Mates, C. Perez-Gomez, and I. Nunez de Castro, "Antioxidant enzymes and human diseases," Clinical Biochemistry, vol. 32, no. 8, pp. 595-603, 1999.

[99] B. Halliwell, "Antioxidants in human health and disease," Annual Review of Nutrition, vol. 16, no. 1, pp. 33-50, 1996.

[100] T. Goto, M. Komai, H. Suzuki, and Y. Furukawa, "Long-term zinc deficiency decreases taste sensitivity in rats," The Journal of Nutrition, vol. 131, no. 2, pp. 305-310, 2001.

[101] J. K. Chesters and M. Will, "Some factors controlling food intake by zinc-deficient rats," The British Journal of Nutrition, vol. 30, no. 3, pp. 555-566, 1973.

[102] C. G. Taylor, W. J. Bettger, and T. M. Bray, "Effect of dietary zinc or copper deficiency on the primary free radical defense system in rats," The Journal of Nutrition, vol. 118, no. 5, pp. 613-621, 1988.

[103] N. Harris, M. Bachler, V. Costa, M. Mollapour, P. MoradasFerreira, and P. W. Piper, "Overexpressed Sod1p acts either to reduce or to increase the lifespans and stress resistance of yeast, depending on whether it is $\mathrm{Cu}^{2+}$-deficient or an active Cu,Zn-superoxide dismutase," Aging Cell, vol. 4, no. 1, pp. 41-52, 2005.

[104] J. C. Barbato, O. Catanescu, K. Murray, P. M. DiBello, and D. W. Jacobsen, "Targeting of metallothionein by L-homocysteine: a novel mechanism for disruption of zinc and redox homeostasis," Arteriosclerosis, Thrombosis, and Vascular Biology, vol. 27, no. 1, pp. 49-54, 2007.

[105] K. Hegetschweiler, P. Saltman, C. Dalvit, and P. E. Wright, "Kinetics and mechanisms of the oxidation of myoglobin by $\mathrm{Fe}(\mathrm{III})$ and $\mathrm{Cu}(\mathrm{II})$ complexes," Biochimica et Biophysica Acta (BBA) - Protein Structure and Molecular Enzymology, vol. 912, no. 3, pp. 384-397, 1987.

[106] A. S. Prasad, "Zinc is an antioxidant and anti-inflammatory agent: its role in human health," Frontiers in Nutrition, vol. 1, p. 14, 2014.

[107] J. C. Ludwig, R. L. Misiorowski, M. Chvapil, and M. D. Seymour, "Interaction of zinc ions with electron carrying coenzymes NADPH and NADH," Chemico-Biological Interactions, vol. 30, no. 1, pp. 25-34, 1980.

[108] W. J. Bettger, T. J. Fish, and B. L. O'Dell, "Effects of copper and zinc status of rats on erythrocyte stability and superoxide dismutase activity," Proceedings of the Society for Experimental Biology and Medicine, vol. 158, no. 2, pp. 279-282, 1978. 
[109] H. Pasantes-Morales and C. Cruz, "Protective effect of taurine and zinc on peroxidation-induced damage in photoreceptor outer segments," Journal of Neuroscience Research, vol. 11, no. 3, pp. 303-311, 1984.

[110] G. L. Floersheim, "Protection against acute ethanol toxicity in mice by zinc aspartate, glycols, levulose and pyritinol," Agents and Actions, vol. 16, no. 6, pp. 580-584, 1985.

[111] G. L. Floersheim and A. Bieri, "Further studies on selective radioprotection by organic zinc salts and synergism of zinc aspartate with WR 2721," The British Journal of Radiology, vol. 63 , no. 750 , pp. 468-475, 1990.

[112] P. K. Singal, K. S. Dhillon, R. E. Beamish, and N. S. Dhalla, "Protective effect of zinc against catecholamine-induced myocardial changes electrocardiographic and ultrastructural studies," Laboratory Investigation, vol. 44, no. 5, pp. 426433, 1981.

[113] S. R. Powell, D. Hall, L. Aiuto, R. A. Wapnir, S. Teichberg, and A. J. Tortolani, "Zinc improves postischemic recovery of isolated rat hearts through inhibition of oxidative stress," American Journal of Physiology-Heart and Circulatory Physiology, vol. 266, no. 6, Part 2, pp. H2497-H2507, 1994.

[114] S. R. Powell, R. L. Nelson, J. M. Finnerty et al., "Zinc-bishistidinate preserves cardiac function in a porcine model of cardioplegic arrest," The Annals of Thoracic Surgery, vol. 64, no. 1, pp. 73-80, 1997.

[115] M. M. Cortese, C. V. Suschek, W. Wetzel, K. D. Kröncke, and V. Kolb-Bachofen, "Zinc protects endothelial cells from hydrogen peroxide via Nrf2-dependent stimulation of glutathione biosynthesis," Free Radical Biology \& Medicine, vol. 44, no. 12, pp. 2002-2012, 2008.

[116] T. Fukada, S. Yamasaki, K. Nishida, M. Murakami, and T. Hirano, "Zinc homeostasis and signaling in health and diseases: zinc signaling," JBIC Journal of Biological Inorganic Chemistry, vol. 16, no. 7, pp. 1123-1134, 2011.

[117] G. Lyubartseva and M. A. Lovell, "A potential role for zinc alterations in the pathogenesis of Alzheimer's disease," BioFactors, vol. 38, no. 2, pp. 98-106, 2012.

[118] K. Smidt and J. Rungby, "ZnT3: a zinc transporter active in several organs," Biometals, vol. 25, no. 1, pp. 1-8, 2012.

[119] S.-J. Lee and J.-Y. Koh, "Roles of zinc and metallothionein-3 in oxidative stress-induced lysosomal dysfunction, cell death, and autophagy in neurons and astrocytes," Molecular Brain, vol. 3, no. 1, p. 30, 2010.

[120] P. W. Land and E. Aizenman, "Zinc accumulation after target loss: an early event in retrograde degeneration of thalamic neurons," The European Journal of Neuroscience, vol. 21, no. 3, pp. 647-657, 2005.

[121] E. Bossy-Wetzel, M. V. Talantova, W. D. Lee et al., "Crosstalk between nitric oxide and zinc pathways to neuronal cell death involving mitochondrial dysfunction and p38-activated $\mathrm{K}^{+}$ channels," Neuron, vol. 41, no. 3, pp. 351-365, 2004.

[122] C. Jacob, W. Maret, and B. L. Vallee, "Ebselen, a seleniumcontaining redox drug, releases zinc from metallothionein," Biochemical and Biophysical Research Communications, vol. 248, no. 3, pp. 569-573, 1998.

[123] A. T. Dinkova-Kostova, W. D. Holtzclaw, and N. Wakabayashi, "Keap1, the sensor for electrophiles and oxidants that regulates the phase 2 response, is a zinc metalloprotein," Biochemistry, vol. 44, no. 18, pp. 6889-6899, 2005.

[124] G. Salazar, J. Huang, R. G. Feresin, Y. Zhao, and K. K. Griendling, "Zinc regulates Nox1 expression through a NF- $\kappa \mathrm{B}$ and mitochondrial ROS dependent mechanism to induce senescence of vascular smooth muscle cells," Free Radical Biology \& Medicine, vol. 108, pp. 225-235, 2017.

[125] M. Malavolta, L. Costarelli, R. Giacconi et al., "Changes in Zn homeostasis during long term culture of primary endothelial cells and effects of $\mathrm{Zn}$ on endothelial cell senescence," Experimental Gerontology, vol. 99, pp. 35-45, 2017.

[126] A. Q. Truong-Tran, L. H. Ho, F. Chai, and P. D. Zalewski, "Cellular zinc fluxes and the regulation of apoptosis/genedirected cell death," The Journal of Nutrition, vol. 130, no. 5, pp. 1459S-1466S, 2000.

[127] B. Hennig, P. Meerarani, P. Ramadass et al., "Zinc nutrition and apoptosis of vascular endothelial cells: implications in atherosclerosis," Nutrition, vol. 15, no. 10, pp. 744-748, 1999.

[128] D. K. Perry, M. J. Smyth, H. R. Stennicke et al., "Zinc is a potent inhibitor of the apoptotic protease, caspase-3. A novel target for zinc in the inhibition of apoptosis," The Journal of Biological Chemistry, vol. 272, no. 30, pp. 18530-18533, 1997.

[129] R. B. Franklin and L. C. Costello, "The important role of the apoptotic effects of zinc in the development of cancers," Journal of Cellular Biochemistry, vol. 106, no. 5, pp. 750757, 2009.

[130] K. M. Noh and J. Y. Koh, "Induction and activation by zinc of NADPH oxidase in cultured cortical neurons and astrocytes," The Journal of Neuroscience, vol. 20, article Rc111, 2000.

[131] M. D. Pluth, E. Tomat, and S. J. Lippard, "Biochemistry of mobile zinc and nitric oxide revealed by fluorescent sensors," Annual Review of Biochemistry, vol. 80, no. 1, pp. 333355, 2011.

[132] M. A. Aras, H. Hara, K. A. Hartnett, K. Kandler, and E. Aizenman, "Protein kinase $\mathrm{C}$ regulation of neuronal zinc signaling mediates survival during preconditioning," Journal of Neurochemistry, vol. 110, no. 1, pp. 106-117, 2009.

[133] H. Haase and W. Maret, "Intracellular zinc fluctuations modulate protein tyrosine phosphatase activity in insulin/ insulin-like growth factor-1 signaling," Experimental Cell Research, vol. 291, no. 2, pp. 289-298, 2003.

[134] D. Ciubotariu, C. M. Ghiciuc, and C. E. Lupusoru, "Zinc involvement in opioid addiction and analgesia - should zinc supplementation be recommended for opioid-treated persons?," Substance Abuse Treatment, Prevention, and Policy, vol. 10, no. 1, p. 29, 2015.

[135] S. R. Lee, S. J. Noh, J. R. Pronto et al., "The critical roles of zinc: beyond impact on myocardial signaling," The Korean Journal of Physiology \& Pharmacology, vol. 19, no. 5, pp. 389-399, 2015.

[136] S. Noh, S. R. Lee, Y. J. Jeong et al., "The direct modulatory activity of zinc toward ion channels," Integrative Medicine Research, vol. 4, no. 3, pp. 142-146, 2015.

[137] W. Q. Ding and S. E. Lind, "Metal ionophores - an emerging class of anticancer drugs," IUBMB Life, vol. 61, no. 11, pp. 1013-1018, 2009. 


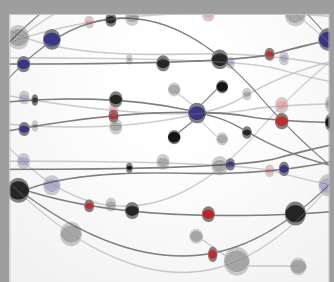

The Scientific World Journal
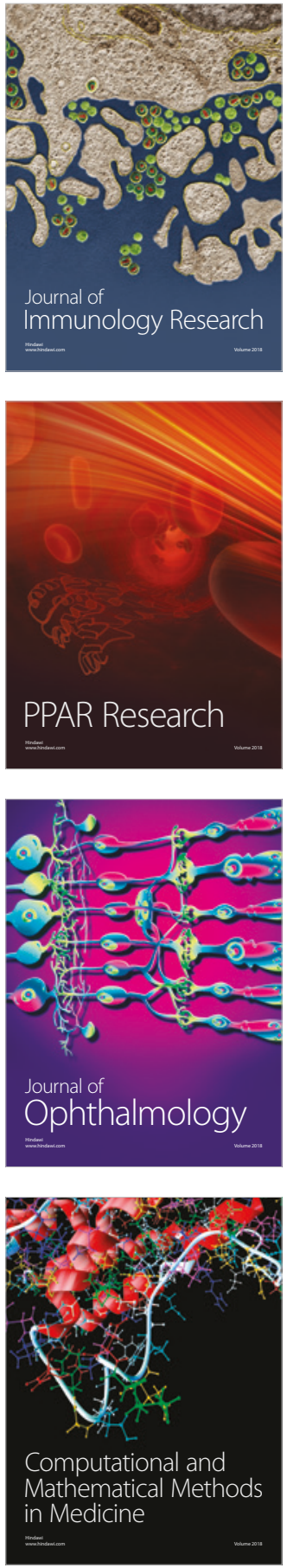

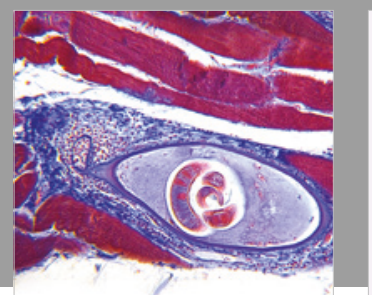

Gastroenterology Research and Practice

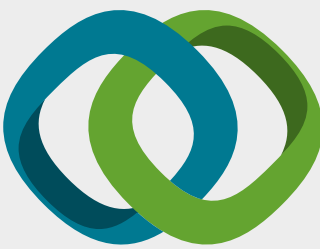

\section{Hindawi}

Submit your manuscripts at

www.hindawi.com
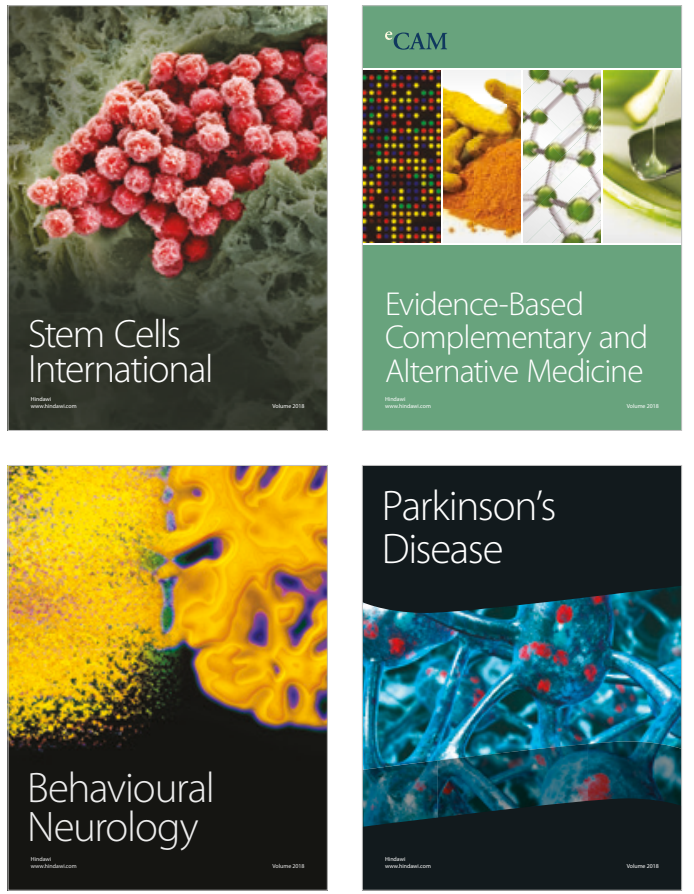

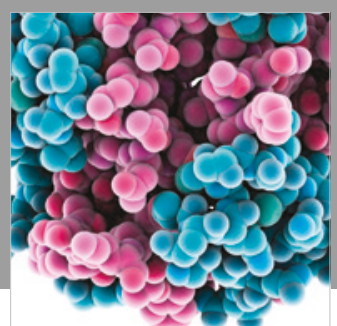

ournal of

Diabetes Research

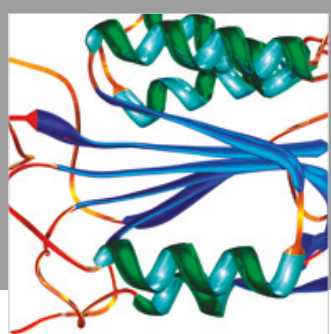

Disease Markers
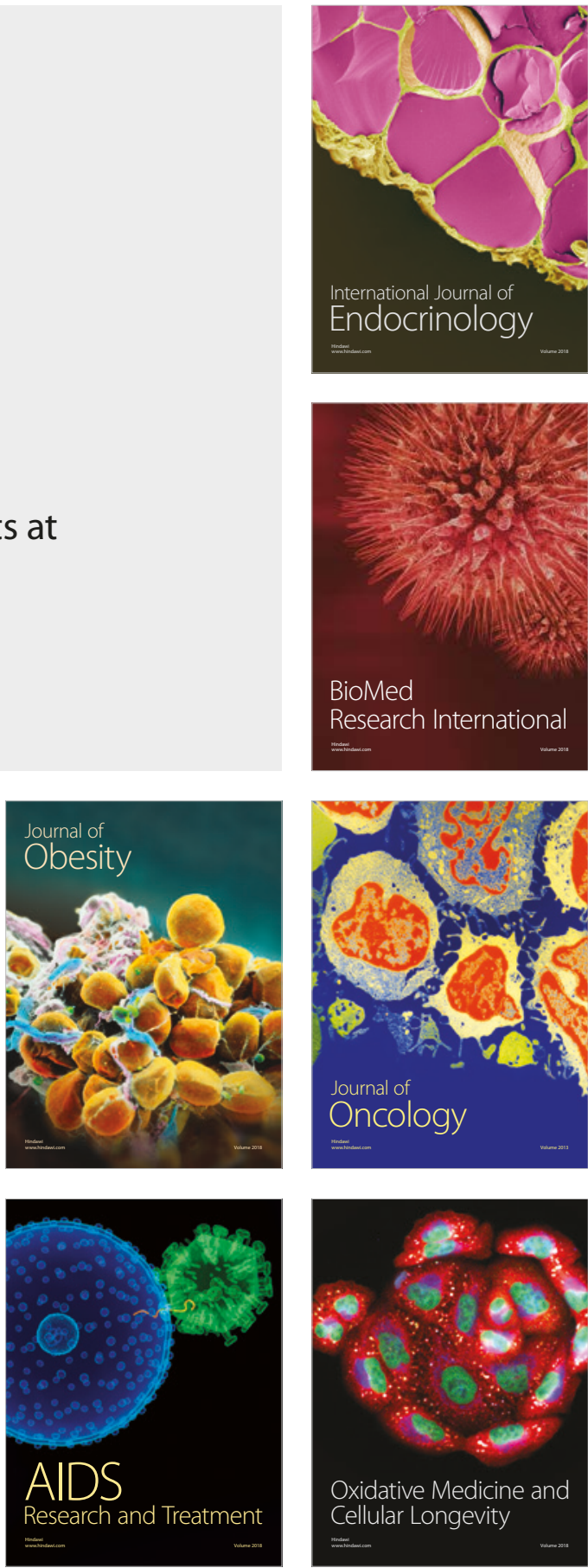